\title{
Computational Design of Carbon Nano-Devices Based on SWCNTs and Active Molecules of Some Natural Extracts
}

\author{
E. Díaz-Cervantes ${ }^{1}$, D. Jáuregui-Vázquez¹, D. Hernández-Méndez ${ }^{1}$, M. R. Abraham-Juárez ${ }^{1}$, F- Aguilera- \\ Granja ${ }^{2}$ \\ ${ }^{1}$ Departamento de Alimentos, Centro Interdisciplinario del Noreste (CINUG), Universidad de Guanajuato, \\ 37975 Tierra Blanca, Guanajuato, México \\ e.diaz@ugto.mx \\ ${ }^{2}$ Instituto de Física, Universidad Autónoma de San Luis Potosí \\ 78000 San Luis Potosí, SLP, México
}

\section{Extended Abstract}

In the northern region of Guanajuato, there are several plants which natural extracts have some applications in both, the medicine and the food fields. Origanum vulgare and Lophophora williamsii are some endemic species of this region and their active molecules have been studied as anticancer and anti-inflammatory alternatives, respectively [1]. The principal therapeutic molecules of these species are the carvacrol, thymol, and mescaline, see Figure 1.<smiles>Cc1ccc(C(C)C)cc1O</smiles><smiles>Cc1ccc(C(C)C)c(O)c1</smiles><smiles>COc1cc(CCN)cc(OC)c1OC</smiles>

Fig. 1: Molecular structures of carvacrol (A), thymol (B) and mescaline (C).

On the other hand, the study of the single wall carbon nanotubes (SWCNTs) is one of the aims in our research group, obtaining in the last years through the formalism of the Density Functional Theory, [2] their possible minimal conformations, electronic structure, apparent solubility and a proposed drug delivery way of these kinds of nanoparticles.[3] For this reason, we are now proposing a functionalized SWCNTs with some active molecules of natural extracts, as carvacrol, thymol, and mescaline, studied at level PBE/6-311G(d,p) [4].

With the selected molecules at the specified level of theory, we computed the model of three drug transport nano-devices with the kindness of an anticancer and an anti-inflammatory drug. Finally, with the optimized structures we are proposing that this nano-devices present an apparent solubility $(<-5 \mathrm{kcal} / \mathrm{mol})$ and an exergonic Gibbs free energies of functionalization $(<-8 \mathrm{kcal} / \mathrm{mol})$.

\section{Acknowledgements}

E. Díaz-Cervantes, acknowledge to "Secretaría de Innovación, Ciencia y Educación Superior (SICES)" and to the "H. Ayuntamiento de Tierra Blanca, Guanajuato", by the support in the Project Q2187, SICES/CONV/051/2018 (Elucidación de la composición de extractos naturales del Noreste de Guanajuato).

\section{References}

[1] C. C. Liolios, O. Gortzi, S. Lalas, J. Tsaknis and I. Chinou, "Liposomal incorporation of carvacrol and thymol isolated from the essential oil of Origanum dictamnus L. and in vitro antimicrobial activity," Food Chem, vol. 112, pp. 77-83, 2009.

[2] R. G. Parr and R. G. Pearson, "Absolute hardness: companion parameter to absolute electronegativity," J. Am. Chem. Soc. vol. 105, pp. 7512-7516, 1983.

[3] E. Díaz-Cervantes, M. A. García-Revilla, J. Robles and F. Aguilera-Granja, "Solubility of functionalized single-wall carbon nanotubes in water: a theoretical study," Theor. Chem. Acc., vol. 136, pp. 127, 2017. 
[4] J. P. Perdew, K. Burke and M. Ernzerhof, “Generalized Gradient Approximation Made Simple,” Phys. Rev. Lett., vol. 77, pp. 3865-3868, 1996. 